\title{
Will the Real Author Please Stand Up!
}

\author{
George Paul
}

Received: 31 March 2011/Accepted: 3 April 2011/Published online: 22 April 2011

(C) Association of Oral and Maxillofacial Surgeons of India 2011

\begin{abstract}
This is a Guest editorial on the ethics of authorship in scientific publications. The editorial analyzes the qualification and roles of an author. It also discusses controversial issues and the relevance of the order of authorship in bio-medical journal publications.
\end{abstract}

In 2010 the Dental Council of India introduced a regulation requiring mandatory publications for promotion and tenure of teachers in Dental institutions around the country [1]. This resulted in a desperate scramble for publication at various levels in academia. One of the conditions imposed by the mandate included the necessity for first authorship in an indexed, peer reviewed journal. In the light of the emerging definition of authorship the need to be the first author did appear rather irrational. In fact the requirement has since been withdrawn by the DCI following objections from various quarters including an open letter from this writer.

Authorship of journals has always been a contentious issue. Sahu et al. [2] have reviewed the evolution of the conflicts and controversies surrounding claims to authorship in scientific publications. There has been much misuse in the inclusion of authorship, resulting in persons with no involvement in a publication being listed. Journals like Science and Lancet ridiculed these trends by dubbing them 'Surprise authorship' and 'Polyauthorship giftosa' [3, 4]. The practice of including spouses, friends and bosses in the author's list is still prevalent in some of our publication practices.

G. Paul ( $\square)$

Paulose Maxillofacial Centre, Salem, India

e-mail: maxfaxgp@gmail.com
There has been considerable debate on this matter and various suggestions including arranging authors according to alphabetic order have been proposed [5]. Today, it is clear that in most instances, it is difficult to give primacy to one or the other author for the simple reason that their contributions might be equal. This is particularly so when the publications relate to multicentre trials where each group may have contributed in equal measure. The International Committee of Medical Journal Editors (ICJME) has laid down clear guidelines for authorship. The fundamental principle, it appears, is to first accept the premise that all or most of the authors may have a substantial stake in the publication and it would be unfair to give primacy to the first author alone. The key word is 'substantial contribution'. The ICJME defines an author (whether first or last) as a person who has made substantial contribution to the publication. It goes on to define 'substantial contribution' as (a) conception and design, or acquisition of or analysis and interpretation of data, (b) drafting the article or revising it critically for important intellectual content, and (c) final approval of the version to be published [6]. The litmus test for authorship appears to be the ability to defend the contents of a publication without any help from the coauthors. It is obvious that an 'honorary' or 'gift' author will not be able to do so!!

A clear distinction must be made between persons who have generally contributed to the publication and valid authorship. The former may be acknowledged in the publication but the author entitlement must go only to the person who has contributed intellectually to the design, drafting, writing and analysis. Authorship also assumes responsibility to accept liability. This brings us to the question of who is not an author. Smith G [7] jocularly says "I can only suggest that holding the door open while rats are brought into the laboratory does not constitute 
authorship". In the same vein a surgeon does not qualify for the simple reason that he had operated on a rare tumour. Similarly, being the head of a department where a study is being conducted does not automatically entitle him or her to claim authorship.

Some of the issues that have caused significant concern are student-faculty conflicts. It is a tenuous relationship built on trust, dependence and respect. Fine and Kurdek [8] have analyzed hypothetical situations to determine authorship of articles extracted out of dissertations and thesis. This is of particular interest in our scenario where guides and heads of departments take first author credit for the supervisory roles played by them. They have relied on the American Psychological Association's (APA's) guidelines that in the case of articles arising out of dissertations, supervisors may be named as authors only if they have made 'substantial contribution' to the study. They go on to assert that in such instances it is appropriate to name them as second authors after reserving the first authorship for the student. This surmise further underlines the fact that, by definition, dissertations are the original property of the student and not the guide. The equation may of course change when deciding ethical principles of Faculty- Student collaborative projects. In these instances the supervisor or primary investigator may decide the level of authorship to be given to the student. While there may be situations where the sequence of authorship is based on the quantum of contribution, this is not necessarily the case in all publications. In fact there may be situations where the first author might in fact have usurped the distinction using his/her position of power. On the other hand one is also likely to encounter situations where the head of the department may choose to be the last author despite 'substantial contribution' and general supervisory roles. In fact it was traditional at one time for heads of departments to accept the place of last author [9]. It is for this reason that authorship will have to be seen as a singular honour irrespective of the sequence or position in the author's list.

Fortunately, today's editorial submission policy includes the need for a clear and precise statement on the role and contribution of each author. This serves to reinforce the principle that authorship can be achieved only on the basis of substantial contribution. It also defines real authorship.

Acknowledgments I wish to acknowledge Dr B. Sivapathasundaram, Professor of Oral Pathology, Meenakshi Ammal Dental College, Chennai, for sharing with me his personal opinions and literature pertaining to publication ethics.

Conflict of interest None.

\section{References}

1. Notification from DCI to all Dental Institutions. Letter Nos DE-142010/A-3481 dated 13th July 2010 and DE-14-2010/A6348 dated 24th September 2010

2. Sahu DR, Abraham P (2000) Authorship: rules, rights, responsibilities and recommendations. J Postgrad Med 46:205

3. Levy GN (1997) Surprise authorship. Science 275:1863

4. Kapoor VK (1995) Polyauthoritis giftosa. Lancet 346:1039

5. Tregenza T (1997) Alphabetical orders. Nature 388:511

6. Davidoff F (2000) News from the International Committee of Medical Journal Editors. Ann Intern Med 133:229-231

7. Smith GM (1996) The meaning of authorship. JAMA 276:1385

8. Fine MA, Kurdek LA (1993) Reflections on determining authorship credit and authorship order on faculty-student collaborations. Am Psychol 48:1141-11478

9. Drenth JP (1998) Multiple authorship. The contribution of senior authors. JAMA 280:219-221 